\title{
Enerji Tüketimi, Finansal Gelişme Ve Ekonomik Büyüme İlişkisi: Hindistan Örneklemi
}

\section{The Relationship Among Energy Consumption, Financial Development and Economic Growth: The Sample of India}

\author{
Buhari DOĞAN, Süleyman Demirel Üniversitesi, Türkiye, doganbuhari@gmail.com \\ Osman DEĞER, Süleyman Demirel Üniversitesi, Türkiye, osmandeger9@gmail.com
}

\begin{abstract}
Öz: Bu çalı̧̧ma enerji tüketimi, finansal gelişme ve ekonomik büyüme ilişkisini, 1970-2013 yılları arasında Hindistan örnekleminde incelemeyi amaçlamış̧tır. Ampirik analiz bölümünde Granger nedensellik, Johansen eşbütünleșme ve uzun dönem analizleri kullanılmıştır. Yapılan nedensellik analizi sonucunda ekonomik büyümeden enerji tüketimine doğru bir nedensellik iliş̧kisi mevcutken enerji tüketiminden ekonomik büyümeye bir nedensellik ilişkisi yoktur. Ayrıca ekonomik büyümeden finansal gelişmeye doğru bir nedensellik ilişkisi bulunmuştur. Eşbütünleşme analizi sonucuna göre seriler arasında bir eşbütünleşme iliş̧isi tespit edilmiştir. Yapılan uzun dönem analizi sonucunda seriler arasinda uzun dönemde enerji tüketimindeki \%1 oranında bir artı̧s ekonomik büyümeyi \%0.98 oranında arttırdı̆̆l görülmüsstür. Ayrıca uzun dönemde finansal gelişmedeki \%1 oranindaki artış ekonomik büyümeyi \% 0.18 artırdığı tespit edilmişstir.
\end{abstract}

Anahtar Sözcükler: Enerji, Finansal Gelişme, Ekonomik Büyüme, Granger Nedensellik, Johansen Eşbütünleşme.

\begin{abstract}
This study aims to investigate the relationships among energy consumption, financial development and economic growth with the sample of India between 1970-2013. Granger causality test, Johansen cointegration test and long term analysis are used for empirical analysis. According to the results of the causality test, there is a causality from economic growth to energy consumption, while there is no causality from energy consumption to economic growth. Also a causality has been found from economic growth to financial development. According to the cointegration test there is cointegration between the series. As a result of the long and short term analysis, it has been seen that $1 \%$ increase of energy consumption increases the economic growth $0.98 \%$ for long term.Also it has been identified that $1 \%$ increase of financial development increases the economic growth $0.18 \%$ for long term.
\end{abstract}

Keywords: Energy, Financial Development, Economic Growth, Granger Causality, Johansen Cointegration.

\section{Giriş}

Enerji, ekonomik gelişmenin temel yapı taşlarındandır (Ghosh 2002,125). Ekonomik büyüme ile enerji tüketimi arasındaki ilişki 40 yıldan beri ekonomi ve politika analizcilerinin öncelikli odak noktası haline gelmiştir (Yang 2000; Ghosh 2002). Küreselleşme ile birlikte değişen ve gelişen koşullarla birlikte enerji tüketiminin ekonomik yansımaları bütün ülkelerin dikkatini çekmeye başlamıştır (Mucuk ve Uysal 2009,107). Günümüz koşullarında vazgeçilmez bir yere sahip olan enerji tüketimi, gün geçtikçe daha önemli hale gelmektedir. Ülkelerin daha fazla mal ve hizmet üretebilmeleri ve yaşam standartlarını yükseltebilmesi enerji kullanımı ile gerçekleşmektedir. Kalkınmanın temelinde, maliyetlerin belirlenmesinde ve büyümenin gerçekleşmesinde her zaman enerji ihtiyacının olması enerjiyi önemli konuma getirmektedir (Bulut vd. 2014, 2). Bu bakımdan enerji ekonomik büyümenin, sanayileşmenin ve şehirleşmenin anahtar kaynağı konumuna gelmiştir (Paul ve Bhattacharya 2004, 977).

Enerji ve büyüme ilişkisi üzerine literatürde iki farklı görüş bulunmaktadır. Enerji yanlısı yaklaşıma göre enerjinin ekonomik büyüme üzerindeki etkisi açıktır ve enerji işgücü ve sermaye gibi assıl girdi faktörüdür. Başka bir deyişle, enerji ekonomik büyümede etkili ana faktörlerdendir. Fakat Neoklasik yaklaşıma göre, büyüme üzerinde enerji tüketiminin etkisinin az olduğu yönündedir. Çünkü Gayri Safi Yurtiçi Hasıla (GSYİH) içinde enerji maliyetlerinin çok düşük miktarda yer tutmasından dolayı enerjinin ekonomik büyüme üzerindeki etki düzeyinin düşük olacağı savunulmaktadır (Aytaç 2010, 483; Bulut vd. 2014, 4). Enerji tüketimi ve ekonomik büyüme arasındaki ilișki ekonomi literatüründe Kraft ve Kraft'ın (1978) çalışmalarından yana en çok incelenen konu olmuştur. Bu konu üzerinde enerji iktisatçılarının ilgisi, özellikle 2005 yılında yürürlüğe giren Kyoto (1997) protokolü kabul edildikten sonra küresel ısınma ile ilgili endişelerinin artmasıyla yeni bir ivme kazanmıştır (Omay vd. 2012, 2)

$\mathrm{Bu}$ çalışma Hindistan örnekleminde enerji tüketimi, finansal gelişme ve ekonomik büyüme arasındaki ilişkiyi Granger Nedensellik ve Johansen Eşbütünleşme testi ile incelemektedir. Çalışmanın örneklemini teşkil eden Hindistan son yıllarda elde ettiği ekonomik büyüme performansıyla, bütün dünyanın ilgisini çekmektedir. Son zamanlarda büyük miktarda Doğrudan Yabancı Yatırım (DYY) çekip bunu içselleştirerek, fason üretimi azaltmasıyla, ürün geliştirici konumuna yükselen Hindistan'ın bu alanda elde ettiği deneyimlerinden, gelişmekte olan ülkelerin çıkaracağı önemli politikalar yer almaktadır (Göçer ve Peker 2014, 109). Bu bağlamda Hindistan hızlı ekonomik gelişme gösteren gelişmekte olan ülkelerin başında gelmesi bakımından çalışmanın örnekleminde kullanılmıştır (Ahmad vd. 2016, 131132). Enerji tüketimi ile ekonomik büyüme arasındaki dinamik ilişkiyi daha iyi anlamak için modele üretim fonksiyonun önemli bir faktörü olan finansal gelişme de dâhil edilmiştir. Finansal gelişme, DYY akışının artışı, gelişmiş borsa ve 
bankacılık faaliyetleri ve olumlu reformları kapsamaktadır (Shahbaz vd. 2013b, 10). Finansal altyapı ekonomik büyümeyi artırabilme ve enerji talebini etkileyebilme gücüne sahiptir. Özellikle çalışmaların çoğu enerji ve finansal gelişmenin bir ekonomide büyüme sürecini artırdığını göstermektedir (Sadorsky, 2010; 2011; 2012; Shahbaz ve Lean 2012). Yani finansal gelişme ekonomik büyüme yoluyla dolaylı olarak enerji tüketimini etkilemektedir. Bu etki ekonomik büyümenin etki yönüne göre negatif ya da pozitif olabilmektedir. Örneğin finans sektöründe sağlanan büyüme üretim faaliyetlerinde genişleme ile yatırım projeleri için fon kullanımını arttırması sanayi genişlemesi/büyümesi ile sonuçlanır. Bu bakımdan ekonomik büyüme sırasıyla daha fazla altyapı ve enerji talebini arttırmaktadır ve böylelikle bu durumdan enerji tüketimi olumlu etkilenmektedir (Komal ve Abbas 2015, 212). Bu bağlamda çalışma enerji tüketimi, finansal gelişme ve ekonomik büyüme arasındaki ilişkiyi bir bütün olarak ele alması yönüyle diğer çalışmalardan ayrılmakta ve bu bakımdan literatüre bir katkı sağlayacağı düşünülmektedir. Enerji tüketimi, ekonomik büyüme ve finansal gelişme arasındaki ilişkinin varlığ 1 ekonomik büyüme, kalkınma ve üretimi doğrudan etkilediği için politika yapıcılar için önem arz etmektedir (Salman ve Atya 2014, 137).

\section{Literatür}

Son zamanlarda enerji ekonomisi akademisyenlerin dikkatini çekmeye başlamıştır. Çoğu çalışmada enerji tüketimi ile ekonomik büyüme ilişkisi incelenmiştir. Enerji tüketimi ile ekonomik büyüme arasındaki ilişki hem ampirik hem de teorik ve politik bakımdan önem taşımaktadır (Odhiambo 2009, 618). Ekonomik büyüme tekerleğinin devam etmesi için enerji önemlidir. Ayrıca kişi başına düşen geliri yüksek olan ülkelerin enerji taleplerinin daha fazla olması göze çarpan bir ilişkidir. Bununla ilgili olarak, ilk çalışma Kraft ve Kraft (1978) tarafindan 1947-1974 dönemi için ABD örnekleminde yapılan çalışmada enerji tüketiminden ekonomik büyümeye doğru tek taraflı nedenselliğin olduğu sonucu bu sezgiyi doğrulamaktadır (Shahbaz vd. 2013a, 2). Çalışmaların çoğu, enerji ile ekonomik büyüme arasındaki nedenselliğin yönünü ve uzun dönem ilişkiyi keşfetmeyi amaçlamaktadır. Ancak enerji ile ekonomik büyüme arasındaki dinamik ilişkiyi daha iyi anlamak için modele farklı değişkeler örneğin nüfus, uluslararası ticaret ve sermaye, kentleşme ve finansal gelişme gibi., dahil edilebilir (Shahbaz vd. 2013a, 2). Literatürdeki enerji tüketimi ve ekonomik büyüme ile ilgili çalışmalara tek ve çok ülkeli çalışmalar olarak yer verilmiştir. Genel itibariyle teorik ve ampirik çalışmalarda enerji tüketimi ile ekonomik büyüme arasında pozitif yönlü bir ilişki olduğu yönündedir. Ancak örneklemin tekli ve çoklu olmasına göre sonuçlar farklılık gösterebilmektedir. Yapılan çalışmada verilen literatür yayımlandığı yıl sırasına göre tabloya eklenmiştir.

Tablo 1: Tek Bir Ülkeyi İnceleyen Çalışmalarda Enerji Tüketimi ve Ekonomik Büyüme İlişkisi

\begin{tabular}{|c|c|c|c|c|}
\hline Yazar & $\ddot{\text { Ulkeler }}$ & $\begin{array}{l}\text { Veri Seti } \\
\text { Periyodu }\end{array}$ & Metod & Sonuç \\
\hline Cheng (1999) & Hindistan & $1952-1995$ & $\begin{array}{l}\text { Johansen } \\
\text { Eşbütünleşme, } \\
\text { Granger } \\
\text { Nedenselliğin } \\
\text { Hsiao } \\
\text { Versiyonu ve } \\
\text { Hata Düzeltme } \\
\text { Modeli (ECM) }\end{array}$ & $\begin{array}{l}\text { Enerji tüketimi, ekonomik büyüme, sermaye } \\
\text { ve işgücü değişkenlerinin kullanıldığ } 1 \\
\text { çalışmada değişiklerin eşbütünleşik olduğu } \\
\text { bulunmuştur. Uzun ve kı dönemde } \\
\text { nedensellik ekonomik büyümeden enerji } \\
\text { tüketimine doğrudur ve kisa dönem de ise } \\
\text { sermayeden ekonomik büyümeye doğru } \\
\text { olduğu sonucuna varılmıştır. }\end{array}$ \\
\hline Yang (2000) & Tayvan & 1954-1997 & $\begin{array}{l}\text { Granger } \\
\text { Nedensellik }\end{array}$ & $\begin{array}{l}\text { Ekonomik büyüme ile enerji tüketimi } \\
\text { arasında çift taraflı nedenselliğin olduğu } \\
\text { sonucunu elde etmiştir. }\end{array}$ \\
\hline Ghosh (2002) & Hindistan & $1950-1997$ & $\begin{array}{l}\text { Granger } \\
\text { Nedensellik }\end{array}$ & $\begin{array}{l}\text { Nedensellik ekonomik büyümeden enerji } \\
\text { tüketimine doğru bulunmuştur. }\end{array}$ \\
\hline $\begin{array}{l}\text { Paul ve Bhattacharya } \\
\text { (2004) }\end{array}$ & Hindistan & $1950-1996$ & $\begin{array}{l}\text { Engle-Granger } \\
\text { Eşbütünleşme } \\
\text { ve Granger } \\
\text { Nedensellik }\end{array}$ & $\begin{array}{l}\text { Enerji tüketimi ile ekonomik } \\
\text { arası̈ndaki nëme } \\
\text { bulunmuştur. }\end{array}$ \\
\hline $\begin{array}{l}\text { Lise ve Montfort } \\
(2005)\end{array}$ & Türkiye & $1970-2003$ & $\begin{array}{l}\text { Engle-Granger } \\
\text { Eşbütünleşme } \\
\text { ve Granger } \\
\text { Nedensellik }\end{array}$ & $\begin{array}{l}\text { Sonuçlara göre, enerji tüketimi ile ekonomik } \\
\text { büyüme arasında eşbütünleşme ilişkisi } \\
\text { bulunmuştur. Ayrıca nedenselliğin } \\
\text { ekonomik büyümeden enerji tüketimine } \\
\text { doğru olduğu bulunmuştur. }\end{array}$ \\
\hline
\end{tabular}


Dogan, B., Deger, O. / Journal of Yasar University, 2016, 11/44, 326-338

\begin{tabular}{|c|c|c|c|c|}
\hline $\begin{array}{l}\text { Mucuk ve } \\
\text { (2009) }\end{array}$ & Türkiye & 1960-2006 & $\begin{array}{l}\text { Johansen } \\
\text { Eşbütünleşme } \\
\text { testi, Granger } \\
\text { Nedensellik, } \\
\text { Etki-Tepki } \\
\text { Fonksiyonu ve } \\
\text { Varyans } \\
\text { Ayriştırmas1 }\end{array}$ & $\begin{array}{l}\text { Bulgulara göre, değişkenler eşbütünleşiktir } \\
\text { ve nedensellik enerji tüketimden ekonomik } \\
\text { büyümeye doğrudur. }\end{array}$ \\
\hline Odhiambo (2009) & Tanzanya & 1971-2006 & ARDL & $\begin{array}{l}\text { Enerji tüketimi ile ekonomik büyüme } \\
\text { arasında uzun dönem ilişkisi vardır. } \\
\text { Nedensellik ise enerji tüketiminden } \\
\text { ekonomik büyümeye doğrudur. }\end{array}$ \\
\hline Tsani (2010) & Yunanistan & 1960-2006 & $\begin{array}{l}\text { Granger } \\
\text { Nedensellik ve } \\
\text { VAR Analizi } \\
\end{array}$ & $\begin{array}{l}\text { Bulunan nedensellik ilişkisi enerji } \\
\text { tüketiminden } \\
\text { doğrudur. }\end{array}$ \\
\hline $\begin{array}{lll}\text { Saatçi } & \text { ve } & \text { Dumrul } \\
(2013) & & \end{array}$ & Türkiye & $1960-2008$ & $\begin{array}{l}\text { (DOLS) } \\
\text { Dinamik En } \\
\text { Küçük Kareler } \\
\text { Yöntemi ve } \\
\text { (FMOLS) } \\
\text { Düzeltilmiş En } \\
\text { Küçük Kareler } \\
\text { Yöntemi }\end{array}$ & $\begin{array}{l}\text { Her iki yöntemde de elde edilen sonuçlara } \\
\text { göre, elektrik tüketiminin büyüme üzerinde } \\
\text { etkili olduğu sonucuna ulaşılmıştır. Uzun } \\
\text { dönemde elektrik tüketimindeki \% } 1 \text { 'lik artış } \\
\text { ekonomik büyümeyi } \% 0.33-\% 0.37 \\
\text { oranında arttırmıştır. }\end{array}$ \\
\hline Pempetzoglou (2014) & Türkiye & $1945-2006$ & $\begin{array}{l}\text { Doğrusal ilişki } \\
\text { için Granger } \\
\text { Nedensellik, } \\
\text { doğrusal } \\
\text { olmayan ilişki } \\
\text { için ise Diks ve } \\
\text { Panchenko } \\
\text { Nedensellik }\end{array}$ & $\begin{array}{l}\text { Ekonomik büyümeden enerji tüketimine } \\
\text { doğru tek yönlü doğrusal olmayan nedensel } \\
\text { bir ilişki saptanmıştır. }\end{array}$ \\
\hline $\begin{array}{lll}\text { Topall1 } & \text { ve } & \text { Alagöz } \\
\text { (2014) } & & \end{array}$ & Türkiye & 1970-2009 & $\begin{array}{l}\text { Johansen } \\
\text { Eşbütünleşme } \\
\text { ve Todo- } \\
\text { Yamamota } \\
\text { Nedensellik }\end{array}$ & $\begin{array}{l}\text { Bulgulara göre, değişkenlerin uzun } \\
\text { dönemde eşbütünleşik olduğu ayrica } \\
\text { nedensellik hem uzun hem de kısa dönemde } \\
\text { ekonomik büyümeden elektrik tüketimine } \\
\text { doğrudur. }\end{array}$ \\
\hline $\begin{array}{l}\text { Dritsaki ve Dritsaki } \\
\text { (2014) }\end{array}$ & Yunanistan & 1960-2009 & ARDL & $\begin{array}{l}\text { Kısa ve uzun dönemde enerji tüketiminden } \\
\text { karbondioksit emisyonlarına, ekonomik } \\
\text { büyümeden enerji tüketimine tek yönlü } \\
\text { nedensellik olduğu sonucuna ulaşmışlardır. }\end{array}$ \\
\hline $\begin{array}{l}\text { Le, Gasbarro ve } \\
\text { Gullen (2014) }\end{array}$ & $\mathrm{ABD}$ & 1966-2011 & $\begin{array}{l}\text { Vektör Hata } \\
\text { Düzeltme } \\
\text { Modeli (VECM) }\end{array}$ & $\begin{array}{l}\text { Elde edilen sonuçlara göre finansal } \\
\text { gelişmenin etkilediğine dair kanıtlar varken } \\
\text { ekonomik büyümenin finansal gelişmeyi } \\
\text { etkilemediği sonucuna varmışlardır. Kisa } \\
\text { dönemde ise ekonomik büyüme ve finansal } \\
\text { gelişme arasında çift yönlü nedensellik } \\
\text { bulunmuștur. }\end{array}$ \\
\hline $\begin{array}{lll}\text { Gövdere } & \text { ve } & \text { Can } \\
(2015) & & \end{array}$ & Türkiye & $1970-2014$ & $\begin{array}{l}\text { Engle-Granger } \\
\text { Eşbütünleşme }\end{array}$ & $\begin{array}{l}\text { Enerji tüketimi ile ekonomik büyüme } \\
\text { arasında uzun dönemli ilişkinin olduğu } \\
\text { sonucuna ulaşılmıştır. }\end{array}$ \\
\hline $\begin{array}{l}\text { Gövdere ve } \quad \text { Can } \\
(2015)\end{array}$ & Türkiye & $1970-2011$ & ARDL & $\begin{array}{l}\text { Elde edilen sonuçlara göre uzun dönemde } \\
\text { enerji tüketimi, dişa açılık, ihracat ve } \\
\text { ithalat büyümeyi etkilemektedir. Ancak, } \\
\text { sabit sermaye yatırımları ve finansal } \\
\text { genişlemenin büyümeye etkisinin istatistikî } \\
\text { olarak anlamsı olduğu gözlenmiştir. Ayrıca } \\
\text { hata düzeltme modeline göre katsayılar } \\
\text { negatif ve istatiksel olarak anlamlıdır. }\end{array}$ \\
\hline $\begin{array}{l}\text { Komal ve Abbas } \\
(2015)\end{array}$ & Pakistan & $1972-2012$ & $\begin{array}{l}\text { Genelleştirilmiş } \\
\text { Momentler } \\
\text { Methodu } \\
\text { (GMM) }\end{array}$ & $\begin{array}{l}\text { Elde edilen bulgulara göre enerji tüketimi } \\
\text { üzerinde ekonomik büyümenin pozitif bir } \\
\text { etkisinin oldugu saptanmıştır. Ayrica } \\
\text { finansal gelişme ekonomik büyüme yoluyla }\end{array}$ \\
\hline
\end{tabular}


Dogan, B., Deger, O. / Journal of Yasar University, 2016, 11/44, 326-338

\begin{tabular}{|l|l|l|l|}
\hline & & & $\begin{array}{l}\text { enerji tüketimini pozitif yönde } \\
\text { etkilemektedir. }\end{array}$ \\
\hline
\end{tabular}

Kaynak(lar): Yazarlar tarafindan oluşturulmuştur.

Tablo 2: Birden Çok Ülkeyi İnceleyen Çalışmalarda Enerji Tüketimi ve Ekonomik Büyüme İlişkisi

\begin{tabular}{|c|c|c|c|c|}
\hline Yazar & $\ddot{\text { Ullkeler }}$ & $\begin{array}{l}\text { Veri Seti } \\
\text { Periyodu }\end{array}$ & Metod & Sonuç \\
\hline $\begin{array}{lll}\text { Asafu } & \text { ve } & \text { Adjaye } \\
(2000) & & \end{array}$ & $\begin{array}{l}\text { Endonezya } \\
\text { Hindistan } \\
\text { Tayland } \\
\text { Filipinler }\end{array}$ & $1973-1995$ & $\begin{array}{l}\text { Granger } \\
\text { Nedensellik } \\
\text { ve Hata } \\
\text { Düzeltme } \\
\text { Modelinin } \\
\text { (ECM) }\end{array}$ & $\begin{array}{l}\text { Kısa dönemde Tayland ve Filipinler } \\
\text { ekonomisinde enerji tüketimi ile ekonomik } \\
\text { büyüme arasında çift yönlü ilişki varken ve } \\
\text { Endonezya ve Hindistan'da ise enerji } \\
\text { tüketiminden ekonomik büyümeye doğru tek } \\
\text { taraflı bir ilişki elde edilmiştir. }\end{array}$ \\
\hline Yemane (2004) & $\begin{array}{l}17 \text { Afrika } \\
\text { Ülkesi }\end{array}$ & $1971-2001$ & $\begin{array}{l}\text { ARDL ve } \\
\text { Toda- } \\
\text { Yamamoto } \\
\text { Nedensellik }\end{array}$ & $\begin{array}{l}\text { Bulgulara göre } 9 \text { ülkenin değişkenleri arasında } \\
\text { uzun dönemli bir ilişki vardır ve nedensellik } 6 \\
\text { ülkede kişi başı GSYH'den kişi başı elektrik } \\
\text { tüketimine doğru ve } 3 \text { ülkede ise elektrik } \\
\text { tüketiminden GSYH'a doğrudur. }\end{array}$ \\
\hline $\begin{array}{l}\text { Apergis ve Payne } \\
(2009)\end{array}$ & $\begin{array}{l}6 \text { Merkez } \\
\text { Amerika } \\
\text { ülkesi }\end{array}$ & $1980-2004$ & $\begin{array}{l}\text { Panel } \\
\text { Eşbütünleşme } \\
\text { ve VECM }\end{array}$ & $\begin{array}{l}\text { Değişkenler eşbütünleşiktir, nedensellik uzun } \\
\text { ve kısa dönemde enerji tüketiminde ekonomik } \\
\text { büyümeye doğrudur. }\end{array}$ \\
\hline Öztürk vd. (2010) & $\begin{array}{l}51 \text { Ülke } \\
\text { Ekonomisi } \\
\text { Düşük gelir } \\
\text { grubu, Alt- } \\
\text { Orta gelir } \\
\text { grubu ve Orta- } \\
\text { Üst gelir } \\
\text { grubu }\end{array}$ & $1971-2005$ & $\begin{array}{l}\text { Panel } \\
\text { Eşbütünleşme } \\
\text { Panel } \\
\text { Nedensellik }\end{array}$ & $\begin{array}{l}\text { Enerji tüketimi ve ekonomik büyüme arasında } \\
\text { eşbütünleşme ilişkisi vardır. Ayrıca düşük } \\
\text { gelir grubu ülkelerde ekonomik büyümeden } \\
\text { enerji tüketimine doğru nedenselliğin olduğu, } \\
\text { alt-orta gelir grubu ve orta- üst gelir grubu } \\
\text { ülkelerde ise çift yönlü nedenselliğin olduğu } \\
\text { saptanmıştır. }\end{array}$ \\
\hline Omay vd. (2012) & G7 Ülkeleri & $1977-2007$ & $\begin{array}{l}\text { Panel } \\
\text { Eşbütünleşme } \\
\text { ve Panele } \\
\text { dayalı VECM }\end{array}$ & $\begin{array}{l}\text { Doğrusal olmayan Eşbütünleşme testi } \\
\text { değişkenlerin Eşbütünleşik olduğu sonucunu } \\
\text { vermiştir. Enerji tüketiminden ekonomik } \\
\text { büyümeye doğru tek taraflı nedensellik } \\
\text { bulunmuştur. }\end{array}$ \\
\hline Fowowe (2012) & $\begin{array}{l}14 \text { Sahra-Altı } \\
\text { Afrika Ülkesi }\end{array}$ & 1971-2004 & $\begin{array}{l}\text { Panel } \\
\text { Eşbütünleşme } \\
\text { Panel } \\
\text { Nedensellik }\end{array}$ & $\begin{array}{l}\text { Uzun dönemde değişkenler arasında } \\
\text { Eşbütünleşme ilişkisi bulunamamıştır. Ancak } \\
\text { tüm örneklem ülkeler için, enerji tüketiminden } \\
\text { ekonomik büyümeye doğru bir nedensellik } \\
\text { bulunmuştur. }\end{array}$ \\
\hline $\begin{array}{l}\text { Esseghir ve Khouni } \\
\text { (2014) }\end{array}$ & $\begin{array}{l}38 \text { Akdeniz } \\
\text { Birliği Üyesi } \\
\text { Ülke }\end{array}$ & $1980-2010$ & $\begin{array}{l}\text { Panel } \\
\text { Eşbütünleşme } \\
\text { Panel ECM } \\
\end{array}$ & $\begin{array}{l}\text { Uzun dönemde değişkenler eşbütünleşiktir. } \\
\text { Nedensellik enerji tüketiminden ekonomik } \\
\text { büyümeye doğru çift yönlüdür. }\end{array}$ \\
\hline Uçan vd.(2014) & $\begin{array}{l}15 \text { Avrupa } \\
\text { Birliği Ülke }\end{array}$ & $1990-2011$ & $\begin{array}{l}\text { Panel } \\
\text { Eşbütünleşme } \\
\text { Panel } \\
\text { Nedensellik }\end{array}$ & $\begin{array}{l}\text { Bulgulara göre; uzun dönemde GSYİH ile } \\
\text { yenilelebilir ve yenilenemeyen enerji tüketimi, } \\
\text { sera gazı emisyonları, araştırma ve kalkınma } \\
\text { arasında ilişki olduğu sonucu elde edilmiştir. } \\
\text { Ayrıca nedensellik yenilemeyen enerji } \\
\text { tüketiminden ekonomik büyümeye doğrudur. }\end{array}$ \\
\hline $\begin{array}{lll}\text { Salman } & \text { ve } & \text { Atya } \\
(2014) & & \end{array}$ & $\begin{array}{l}\text { Kuzey Afrika } \\
\text { Ülkeleri }\end{array}$ & $1980-2010$ & $\begin{array}{l}\text { Granger } \\
\text { Nedensellik,H } \\
\text { ata Düzeltme } \\
\text { Modeli } \\
(\text { ECM) }\end{array}$ & $\begin{array}{l}\text { Cezayir ve Tunus'da finansal gelişme ve enerji } \\
\text { tüketiminin büyümeye güçlü pozitif katk1 } \\
\text { sağladığını, Mısır'da ise güçlü negatif bir etki } \\
\text { olduğunu tespit etmişlerdir. }\end{array}$ \\
\hline $\begin{array}{l}\text { Siddique ve Majeed } \\
\text { (2015) }\end{array}$ & $\begin{array}{l}5 \text { Güney Asya } \\
\text { Ülkesi }\end{array}$ & $1980-2010$ & $\begin{array}{l}\text { Panel } \\
\text { Eşbütünleşme }\end{array}$ & $\begin{array}{l}\text { Finansal gelişme, enerji ve ticaretin büyümeyi } \\
\text { pozitif etkilediği sonucuna varılmıştır. Uzun } \\
\text { dönemde büyüme ile enerji tüketimi arasında } \\
\text { çift taraflı ilişki varken ticaret ve finansal } \\
\text { gelişmeden büyümeye doğru tek yönlü } \\
\text { nedensellik bulmuşlardır. }\end{array}$ \\
\hline
\end{tabular}

Kaynak(lar): Yazarlar tarafindan oluşturulmuştur. 


\section{Ampirik Analiz}

\subsection{Veri Seti}

Hindistan'ın enerji tüketimi, ekonomik büyüme ve finansal gelişmesi arasındaki nedensellik, eşbütünleşme, uzun ve kısa dönem ilişkisini incelemek için 1970-2013 yıllarına ait yıllık büyüme rakamları, toplam enerji tüketimi (petrol+doğal gaz+kömür+ nükleer enerji + hidroelektrik (su) enerji) ve finansal gelişmeyi gösteren özel sektöre sağlanan kredi serileri kullanılmıştır. Toplam enerji tüketimi verisi, BP (British Petroleum) dünya enerji istatistikleri veri tabanından, büyüme ve finansal gelişme verisi, Dünya Bankası Veri Tabanından temin edilmiştir.

Tablo 3: Veriler

\begin{tabular}{|l|l|l|l|l|}
\hline Değişken & $\begin{array}{l}\text { Elde } \\
\text { Edilmesi }\end{array}$ & Kısaltması & Birimi & Kullanım Biçimi \\
\hline $\begin{array}{l}\text { Hindistan'ın Büyüme } \\
\text { Rakamları }\end{array}$ & $\begin{array}{l}\text { GDP Per } \\
\text { Capita } \\
\text { (Constant } \\
\text { 2005 US\$) }\end{array}$ & GDP & Milyon Dolar & Logaritmik \\
\hline $\begin{array}{l}\text { Hindistan'ın Enerji } \\
\text { Tüketimi }\end{array}$ & $\begin{array}{l}\text { Petrol+ Doğal } \\
\text { Gaz+ Kömür+ } \\
\text { Nükleer } \\
\text { Enerji+ Hydro } \\
\text { Enerji }\end{array}$ & Energy & Mtoe & Logaritmik \\
\hline $\begin{array}{l}\text { Hindistan'ın Finansal } \\
\text { Gelişmesi }\end{array}$ & $\begin{array}{l}\text { Özel Sektöre } \\
\text { Sağlanan } \\
\text { Yurtiçi } \\
\text { Krediler }\end{array}$ & FD & GDP\% & Logaritmik \\
\hline
\end{tabular}

\subsection{Yöntem}

$\mathrm{Bu}$ çalışmada önce serilerin durağanlığı; Augmented Dickey Fuller (ADF) ve PP birim kök analizi yöntemiyle incelenmiştir. Bu yöntemlerden ADF; genel kullanıma sahip olduğu için kullanılmış, PP birim kök analizi ise trend içeren serilerde sıkça kullanıldığından dolayı tercih edilmiştir. Seriler arasında nedensellik ilişkisinin varlığı, Granger nedensellik testiyle incelenmiştir. Seriler arasında eşbütünleşme ilişkisinin varlığı ise Johansen Eşbütünleşme yöntemiyle test edilmiştir. Yapılan eşbütünleşme analizi sonucunda uzun ve kısa dönem analizleri VEC Modeli ile incelenmiştir. Birim kök analizine geçmeden önce serilerin elde edilişleri, kullanılan birimleri ve çalışmada kullanım biçimleri tablo 3' te verilmiştir.

\subsection{Birim Kök Testi}

\subsubsection{ADF Birim Kök}

Zaman serileri analizlerinde seriler durağan olmadıklarında sahte regresyon problemi oluşmaktadır (Karaçor ve Gerçeker 2012, 289-312). Analiz sonucunda oluşturulan serilerin trendleri t, F ve Ki Kare değerlerinin tahmin etmede yetersiz kaldığından dolayı serilerin durağan hale getirilmesi gerekmektedir ve bu şekilde serilerin tahmininde yardımcı olmaktadır (Uzgören vd. 2007, 250). Yapılan ADF testi sonucunda elde edilen ADF test istatistik değerinin mutlak değer içindeki sonucu test sonucunda elde edilen kritik değerden daha büyük olması durumunda serinin durağan olduğu sonucuna ulaşılır. Bunun yanında eğer test istatistiği değeri kritik değerden küçük olursa serinin durağan olmadığ1 sonucu görülmektedir (Barışık ve Demircioğlu 2006, 74). Dickey-Fuller (1981) otokolerasyon bulunan hata terimlerinin saf rastsal olduğu varsayımıyla DF dağılımının geçersiz olması nedeniyle hata terimlerinin eşitliğin sağ tarafında bulunacağını ön görmüştür. Yapılan çalışmalar sonucunda genişletilmiş Dickey-Fuller (Augmented Dickey Fuller: ADF) test istatistiği geliştirilmiştir. ADF testi şu modellerle gerçekleştirilmektedir:

Yalin Model:

Sabitli Model:

Sabitli ve Trendli Model

$$
\Delta Y_{t}=\gamma Y_{t-1}+\sum_{i-1}^{m} \Delta Y_{t-i}+u_{t}
$$

$$
\Delta Y_{t}=\propto_{0}+\gamma Y_{t-1}+\sum_{i-1}^{m} \Delta Y_{t-i}+u_{t}
$$


Yapılan testlere göre ortaya çıkan istatistikler MacKinnon (1996) kritik değerleriyle karşılaştırılır ve serinin sıfır hipotezi $(\mathrm{H} 0: \gamma=0)$, alternatif hipoteze karşı $(\mathrm{H} 1: \gamma \neq 0)$ test edilir. Burada sıfır hipotezi serinin durağan olmadığını gösterirken alternatif hipotez serinin durağan olduğunu ifade etmektedir. Modelde ifade edilen, m; gecikme uzunluğunu, $\Delta$; serilerin farkının alındığını göstermektedir. Yapılan testte gecikme kriteri olarak Schwarz Bilgi Kriteri (SIC) kullanılmıştır. Elde edilen test sonuçları Tablo 4'de gösterilmiştir.

Tablo 4: ADF Birim Kök Testi Sonuçları

\begin{tabular}{|c|c|c|c|c|}
\hline \multirow{2}{*}{ Değişken } & \multirow{2}{*}{$\begin{array}{ll}\text { ADF } & \text { Test } \\
\text { İstatistiği } & \end{array}$} & \multicolumn{3}{|c|}{ Kritik Dĕ̆gerler } \\
\hline & & $\% 1$ & $\% 5$ & $\% 10$ \\
\hline Ln GDP & $-1.416[0]$ & -4.186 & -3.518 & -3.189 \\
\hline Ln Energy & $-2.500[0]$ & -4.186 & -3.518 & -3.189 \\
\hline Ln FD & $-1.527[0]$ & -4.186 & -3.518 & -3.189 \\
\hline$\Delta$ Ln GDP & $-5.396[0]^{*}$ & -3.596 & -2.933 & -2.604 \\
\hline$\Delta$ Ln Energy & $-7.289[0]^{*}$ & -3.596 & -2.933 & -2.604 \\
\hline$\Delta \mathrm{Ln} F D$ & $-3.427[1]^{* *}$ & -3.600 & -2.935 & -2.605 \\
\hline
\end{tabular}

Not: Analizin düzey değerlerinde sabit terim ve trendli, birinci farkda ise, sabit terimli modeller kullanılmıștır. Serilerin düzey değerlerinde sabit ve trend, birinci farkında ise sabitli model tercih edilmesinin nedeni; serilerin birim kök analizinin yapılmasından önce grafiklerinin kontrol edilmiş olup trend içerdiği için sabit ve trendli, birinci farkı alındıktan sonra serilerin grafikleri trend içerdemiği için birinci farkta sabit terimli modeler kullanılmasına karar verilmiştir. [ ] içindeki değerler; Schwarz bilgi ölçütüne (Schwarz Information Criterion: SC) göre belirlenmiş optimal gecikme uzunluğunu göstermektedir; * $\% 1$ anlamlılık düzeyinde durağanlığı ifade etmektedir.**\%5 anlamlılık düzeyini göstermektedir.

Tablo 4'deki sonuçlara bakıldığında ekonomik büyüme, toplam enerji tüketimi ve finansal gelişme serilerinin düzey değerinde $\mathrm{I}(0)$ durağan olmadığını birinci farkta I(1) durağan olduğu görülmektedir.

\subsubsection{Philips-Perron Birim Kök}

Trend içeren serilerin test edilmesinde kullanılan Phillips-Perron birim kök testi ADF testine göre daha güçlü olduğu kabul edilmektedir (Perron,1990). PP birim kök testinde MA (Moving Average: Hareketli Ortalama) teste dahil edilmesi durağanlık testine trend eklenmesi testi daha güçlü hale getirmiştir (Perron,1990). ADF testine göre hata terimlerinin bağımsız ve varyanslarının sabit olduğu varsayılmaktadır (Tarı,2014:400). Phillips-Perron (1988) ADF testine göre belirlenen bu hata terimlerinin varsayımlarını geliştirmiş ve parametrik olmayan birim kök testi oluşturulmuştur. PP, Dickey-Fuller testindeki denklemlerde bulunan parametreye ait olan $\tau$ istatistiğinde parametrik bulunmayan düzeltmeler yaparak içsel bağıntı sorunu çözüme ulaştırmıştır ve PP, Newey- West hata düzeltme modelini kullanarak otokolerasyon sorununu ortadan kaldırmıştır (Göçer ve Özdemir 2012, 202). Yapılacak birim kök testinde kullanılacak denklem aşağıdaki gibidir:

$$
\Delta Y_{t}=\beta_{0}+\theta Y_{t-1}+\beta_{1}\left(t-\frac{T}{2}\right)+u_{t}
$$

Burada $T$; serinin gözlem sayısıdır.

Hipotezlerin değerlendirilmesi ADF testi ile aynıdır. Yani;

$$
\begin{gathered}
H_{0}: \theta=0 \text { ise seri durağan olmamaktadır } \\
H_{1}: \theta<0 \text { ise seri durağandır. }
\end{gathered}
$$

Hipotezleri test etmek için yine MacKinnon (1996) kritik değerleri kullanılabilmektedir. Yapılan PP testi sonuçları tablo 5 'te gösterilmiştir.

Tablo 5'deki sonuçlara bakıldığında ekonomik büyüme, toplam enerji tüketimi ve finansal gelişme serilerinin düzey değerinde $\mathrm{I}(0)$ durağan olmadığını birinci farkta I(1) durağan olduğu görülmektedir. 
Tablo 5: PP Birim Kök Testi Sonuçları

\begin{tabular}{|c|c|c|c|c|}
\hline \multirow{2}{*}{ Değişken } & \multirow{2}{*}{$\begin{array}{ll}\text { PP } & \text { Test } \\
\text { Istatistiği } & \end{array}$} & \multicolumn{3}{|c|}{ Kritik Dĕ̆erler } \\
\hline & & $\% 1$ & $\% 5$ & $\% 10$ \\
\hline Ln GDP & $-1.399[3]$ & -4.186 & -3.518 & -3.189 \\
\hline Ln Energy & $-2.689[3]$ & -4.186 & -3.518 & -3.189 \\
\hline Ln FD & $-1.839[4]$ & -4.186 & -3.518 & -3.189 \\
\hline$\Delta$ Ln GDP & $-5.396[4]^{*}$ & -3.596 & -2.933 & -2.604 \\
\hline$\Delta$ Ln Energy & $-7.267[2]^{*}$ & -3.596 & -2.933 & -2.604 \\
\hline$\Delta \mathrm{Ln} F D$ & $-6.014[4]^{*}$ & 3.596 & -2.933 & -2.604 \\
\hline
\end{tabular}

Not: Düzey değerlerinde sabit terim ve trendli, birinci farkta ise, sabit terimli modeller kullanılmıştır. Serilerin düzey değerlerinde sabit ve trend, birinci farkında ise sabitli model tercih edilmesinin nedeni; serilerin birim kök analizinin yapılmasından önce grafiklerinin kontrol edilmiş olup trend içerdiği için sabit ve trendli, birinci farkı alındıktan sonra serilerin grafikleri trend içerdemiği için birinci farkta sabit terimli modeler kullanılmasına karar verilmiştir. Köşeli parantez içindeki değerler, Newey-West ölçütü kullanılarak tespit edilmiş band genişliğini gösterir. *; \%1 anlamlılık düzeyinde durağanlığı ifade etmektedir.

\subsection{Granger Nedensellik Testi}

İktisadi değişkenler arasındaki ilişkinin yönü iktisat teorisi tarafından belirlenemediği durumlarda, değişkenler arasındaki etkileşimin varlığı ve yönü, Granger (1969) testi ile belirlenebilmektedir. Bu testte değişkenler bağımlı-bağımsız olarak ayrılmamaktadır. Granger nedensellik testinde değişkenler arasındaki etkileşim eşanlı olarak analiz edilebilmektedir.

Granger nedensellik testi, şu modeller yardımıyla gerçekleştirilmektedir:

$$
\begin{aligned}
& \mathbf{X}_{\mathbf{t}}=\sum_{\mathrm{i}=1}^{\mathrm{m}} \alpha_{\mathrm{i}} \mathbf{X}_{\mathrm{t}-\mathrm{i}}+\sum_{\mathrm{i}=1}^{\mathrm{m}} \boldsymbol{\beta}_{\mathrm{i}} \mathbf{Y}_{\mathrm{t}-\mathrm{i}}+\mathbf{u}_{\mathrm{t}} \\
& \mathbf{Y}_{\mathbf{t}}=\sum_{\mathrm{i}=1}^{\mathrm{m}} \boldsymbol{\theta}_{\mathbf{i}} \mathbf{Y}_{\mathrm{t}-\mathbf{i}}+\sum_{\mathrm{i}=1}^{\mathrm{m}} \boldsymbol{\gamma}_{\mathrm{i}} \mathbf{X}_{\mathrm{t}-\mathbf{i}}+\mathbf{u}_{\mathrm{t}}
\end{aligned}
$$

Burada denklem 3.4'de X'in tahminine Y'nin gecikmeli (geçmiş) değerlerinin eklenmesi, X'in öngörü performansını artırıorsa, Y, X'in bir nedenidir denir. Bunun anlamı; Y, X'i etkilemektedir demektir. Yoksa X'in kesin bir nedeni Y'dir demek değildir.

Ho: $\boldsymbol{\beta}_{\mathbf{i}}=\mathbf{0}$ yani $\mathrm{Y}$ değiş̧keninden $\mathrm{X}$ değişkenine doğru bir nedensellik ilişkisi yoktur.

$\mathbf{H}_{1}$ : X değişkeninden Y değişkenine doğru bir nedensellik ilişkisi vardır.

Test, denklem 1'deki $\boldsymbol{\beta}_{\mathbf{i}}$ 'lerin grup halinde sıfira eşit olup olmadığı incelenmektedir. $\boldsymbol{\beta}_{\mathbf{i}}$ katsayıları, belirli bir anlamlılık düzeyinde sıfirdan farklı bulunursa, Y'nin, X'in bir nedeni olduğu sonucuna varılmaktadır. Yani Y'den X'e doğru tek yönlü bir nedensellik ilişkisinin var olduğuna karar verilir.

Benzer şekilde denklem 3.5'de yer alan $\boldsymbol{\gamma}_{\mathbf{i}}{ }^{\prime}$ ler belirli bir anlamlılık düzeyinde sıfirdan farklı bulunursa, X, Y'nin bir nedenidir (nedenselidir, Granger nedenselidir) denir. Bu durumda X, Y'yi anlamlı düzeyde etkilemektedir. X'ten Y'ye bir nedensellik ilişkisinin var olduğuna karar verilir. Bu durumda etkinin artırma yönünde mi yoksa azaltma yönünde mi olduğu belirlenememektedir. Sadece etki var mı yok mu belirlenmektedir.

Her ikisi de $\left(\boldsymbol{\beta}_{\mathbf{i}}, \boldsymbol{\gamma}_{\mathbf{i}}\right)$ sıfırdan farklı ise ikisi de birbirini etkilemektedir. Bu durumda değişkenler arasında iki yönlü nedensellik ilişkisinin var olduğuna karar verilmektedir. İki parametrede sıfıra eşit olduğunda değişkenler arasında bir nedensellik ilişkisinin olmadığına karar verilmektedir.

Nedensellik analizi için bu çalışmada kullanılacak modeller aşağıdaki şekilde düzenlenmiştir:

$$
\mathrm{GDP}_{\mathrm{t}}=\gamma_{0}+\sum_{\mathrm{i}=1}^{\mathrm{m}} \gamma_{\mathrm{i}} \mathrm{GDP}_{\mathrm{t}-\mathrm{i}}+\sum_{\mathrm{i}=1}^{\mathrm{m}} \boldsymbol{\theta}_{\mathrm{i}} \mathrm{ENERGY}_{\mathrm{t}-\mathrm{i}}+\boldsymbol{\vartheta}_{\mathrm{t}}
$$




$$
\begin{aligned}
& \text { ENERGY }_{t}=\varphi_{0}+\sum_{i=1}^{m} \varphi_{i} \text { ENERGY }_{t-i}+\sum_{i=1}^{m} \delta_{i} G D P_{t-i}+\varepsilon_{i} \\
& \mathrm{GDP}_{\mathrm{t}}=\sigma_{0}+\sum_{\mathrm{i}=1}^{\mathrm{m}} \sigma_{\mathrm{i}} \mathrm{GDP}_{\mathrm{t}-\mathrm{i}}+\sum_{\mathrm{i}=1}^{\mathrm{m}} \boldsymbol{\vartheta}_{\mathrm{i}} \mathrm{FD}_{\mathrm{t}-\mathrm{i}}+\boldsymbol{\vartheta}_{\mathrm{t}} \\
& \mathrm{FD}_{\mathrm{t}}=\alpha_{0}+\sum_{\mathrm{i}=1}^{\mathrm{m}} \alpha_{\mathrm{i}} \mathrm{FD}_{\mathrm{t}-\mathrm{i}}+\sum_{\mathrm{i}=1}^{\mathrm{m}} \boldsymbol{\vartheta}_{\mathrm{i}} \mathrm{GDP}_{\mathrm{t}-\mathrm{i}}+\boldsymbol{\vartheta}_{\mathrm{t}} \\
& \text { ENERGY }_{t}=\rho_{0}+\sum_{i=1}^{m} \rho_{i} \text { ENERGY }_{t-i}+\sum_{i=1}^{m} \tau_{i} \text { FD }_{t-i}+\vartheta_{t} \\
& \mathrm{FD}_{\mathrm{t}}=\boldsymbol{\delta}_{\mathbf{0}}+\sum_{\mathrm{i}=1}^{\mathrm{m}} \boldsymbol{\delta}_{\mathbf{i}} \mathrm{FD}_{\mathrm{t}-\mathrm{i}}+\sum_{\mathrm{i}=1}^{\mathrm{m}} \boldsymbol{\tau}_{\mathbf{i}} \mathrm{ENERGY}_{\mathrm{t}-\mathrm{i}}+\boldsymbol{\vartheta}_{\mathrm{t}}
\end{aligned}
$$

Tarı'ya göre nedensellik kavramı ve analizinin aşamaları şu şekilde açıklanabilir (Tarı, 2014: 437-439).

Burada, test edilen hipotez, $\sum_{\mathbf{i}=\mathbf{1}}^{\mathbf{m}} \boldsymbol{\beta}_{\mathbf{i}}=0$ olup $\mathbf{G D P}_{\mathbf{t}-\mathbf{1}} \ldots \ldots \mathbf{G D P}_{\mathbf{t}-\mathbf{m}}$ gecikmeli değişkenlerin ilişkide yeri olmadığı GDP'den ENERGY'e doğru bir nedensellik ilişkisinin olmadığı anlamına gelir. Alternatif hipotez ise $\sum_{\mathbf{i}=\mathbf{1}}^{\mathbf{m}} \mathbf{b}_{\mathbf{i}} \neq 0$ olup ENERGY'den GDP'ye nedensellik olduğunu gösterir.

Kısıtlamalı ilişkilerde hata terimlerinin toplamının bulunması;

$\sum_{\mathrm{i}=\mathbf{1}}^{\mathrm{m}} \boldsymbol{\beta}_{\mathbf{i}} \mathbf{G D P}_{\mathbf{t}-\mathbf{i}}$ terimi dışarıda bırakılarak geride kalan:

$$
\mathbf{G D P}_{\mathbf{t}}=\mathbf{a}_{\mathbf{0}}+\sum_{\mathrm{i}=1}^{\mathrm{m}} \mathbf{a}_{\mathrm{i}} \mathbf{G D P}_{\mathrm{t}-\mathrm{i}}+\mathbf{u}_{\mathbf{t}}
$$

ilişkisi tahmin edilir ve hata terimleri katsayıları toplamı $\sum_{\mathbf{t}=\mathbf{1}}^{\mathbf{n}} \mathbf{e}_{\mathbf{t}}^{2}$ olarak bulunur.

Kısıtlamasız ilişkilerde hata terimlerinin katsayılarının toplamı;

$$
\text { ENERGY }_{t}=a_{0}+\sum_{i=1}^{m} a_{i} \text { ENERGY }_{t-i}+\sum_{i=1}^{m} \beta_{i} G P_{t-i}+u_{i}
$$

şeklinde olan hata terimleri kareleri toplamı; $\sum_{\mathbf{t}=\mathbf{1}}^{\mathbf{n}} \mathbf{u}_{\mathbf{t}}^{2}$ olarak bulunur.

Test istatistiğinin hesaplanması için F değeri hesaplanması aşağıdaki gibidir.

$$
\mathbf{F}=\frac{\left(\mathbf{R S S}_{\mathbf{R}}-\mathbf{R S S}_{\mathrm{UR}}\right) / \mathbf{m}}{\mathbf{R S S}_{\mathrm{UR}} /(\mathbf{n}-\mathbf{k})}
$$

Burada; $R_{S} S_{R} ; \boldsymbol{k}$ lsıtlamall ilişkideki hata terimleri kareleri toplaml, $\boldsymbol{R S S}_{U R}$ kısıtlamasız ilişkideki hata terimleri kareleri toplamıdır. m; dışarıda bırakılan gecikmeli değişken (kısıt) sayısı, n; örnek hacmi ve k; parametre sayısını gösterir. Tablo değerlerinin bulunması; F tablosu üzerinden gösterilir.

Karşılaştırma ve karar aşaması. Bu aşamada hesaplanan F değeri tabloda bulunan F değerinden küçük ise GDP'den ENERGY'ye doğru nedensellik ilişkisi olmadığı hipotezi kabul edilir. Büyük ise hipotez reddedilerek, GDP'den ENERGY'ye nedensellik ilişkisi vardır hipotezi kabul edilir.

Bu açıklamalar ışığında çalışmada Granger nedensellik testi yapılmış ve ortaya çıkan bulgular tablo 5 'te gösterilmiştir. 
Dogan, B., Deger, O. / Journal of Yasar University, 2016, 11/44, 326-338

Tablo 6: Granger Nedensellik Testi

\begin{tabular}{|c|c|c|c|c|}
\hline \multicolumn{2}{|l|}{ Değişkenler } & \multirow{2}{*}{$\begin{array}{l}\text { F Istatistiği } \\
2.17209\end{array}$} & \multirow{2}{*}{$\begin{array}{l}\text { Olasılık Değeri } \\
\\
0.1486\end{array}$} & \multirow{2}{*}{$\begin{array}{l}\text { Karar } \\
\text { Enerji tüketiminden ekonomik } \\
\text { büyümeye doğru bir } \\
\text { nedensellik ilişkisi } \\
\text { bulunmamaktadır. }\end{array}$} \\
\hline $\begin{array}{l}\Delta \text { LnENERGY } \\
\text { LnGDP }\end{array}$ & $\Delta$ & & & \\
\hline $\begin{array}{l}\triangle \mathrm{LnGDP} \\
\text { LnENERGY }\end{array}$ & $\Delta$ & 3.43533 & $0.0714 * *$ & $\begin{array}{l}\text { Ekonomik büyümeden enerji } \\
\text { tüketimine doğru bir } \\
\text { nedensellik ilişkisi } \\
\text { bulunmaktadır. }\end{array}$ \\
\hline $\begin{array}{l}\Delta \mathrm{LnFD} \\
\mathrm{LnGDP}\end{array}$ & $\Delta$ & 0.29365 & 0.5910 & $\begin{array}{l}\text { Finansal gelişmeden milli } \\
\text { gelire doğru bir nedensellik } \\
\text { ilişkisi bulunmamaktadır }\end{array}$ \\
\hline $\begin{array}{l}\Delta \text { LnGDP } \\
\text { LnFD }\end{array}$ & $\Delta$ & 4.71803 & $0.0360 *$ & $\begin{array}{l}\text { Ekonomik büyümeden finansal } \\
\text { gelişmeye doğru bir } \\
\text { nedensellik ilişkisi } \\
\text { bulunmaktadır. }\end{array}$ \\
\hline $\begin{array}{l}\triangle \mathrm{LnFD} \\
\text { LnENERGY }\end{array}$ & $\Delta$ & 2.05905 & 0.1593 & $\begin{array}{l}\text { Finansal gelişmeden enerji } \\
\text { tüketimine doğru bir } \\
\text { nedensellik ilişkisi } \\
\text { bulunmamaktadır. }\end{array}$ \\
\hline $\begin{array}{l}\Delta \text { LnENERGY } \\
\text { LnFD }\end{array}$ & $\Delta$ & 0.06284 & 0.8034 & $\begin{array}{l}\text { Enerji tüketiminden finansal } \\
\text { gelişmeye doğru bir } \\
\text { nedensellik ilişkisi } \\
\text { bulunmamaktadır. }\end{array}$ \\
\hline
\end{tabular}

Not: Optimum gecikme uzunluğu; LR, FPE, AIC, SC ve HQ kriterleri baz alınarak 1 olarak belirlenmiştir. *\%5 anlamlılık düzeyi, **\%10 anlamlılık düzeyini göstermektedir.

Yapılan Granger Nedensellik analizinin sonucunda toplam enerji tüketiminden ekonomik büyümeye doğru bir nedensellik ilişkisi yokken ekonomik büyümeden toplam enerji tüketimine doğru bir nedensellik ilişkisi tespit edilmiştir. Finansal gelişmeden ekonomik büyümeye doğru bir nedensellik yokken ekonomik büyümeden finansal gelişmeye doğru bir nedensellik ilişkisi mevcuttur. Ayrıca finansal gelişme ile toplam enerji tüketimi arasında çift yönlü nedensellik ilişkisi tespit edilememiştir.

\subsection{Johansen Eşbütünleşme Testi}

İlk olarak Engle ve Granger (1987) tarafından bulunan tek denklemli eşbütünleşme analizi, daha sonra Johansen (1988) ve Johansen ve Juselius (1990), tarafından çok denklemli (eşanlı denklem sistemine sahip) olarak geliştirilmiştir. VAR modelinin temelli olan Johansen eşbütünleşme yöntemi, modelde birden fazla bağımsız değişken bulunduğunda bu seriler arasındaki birden fazla eşbütünleşme ilişkilerini tespit etmede güçlü kabul edilmektedir.

$$
Y_{t}=A_{1} Y_{t-1}+\cdots+A_{p} Y_{t-p}+B X_{t}+\varepsilon_{t}
$$

Burada $\mathbf{y}_{\mathbf{t}}$; düzeyde durağan olmayan $\mathrm{I}(1)$ değişkenlerinin bir $\mathrm{k}$ vektörünü, $\mathbf{x}_{\mathbf{t}}$; deterministik değişkenlerin bir d vektörünü, $\boldsymbol{\varepsilon}_{\mathbf{t}}$ ise, yenilik (innovation) vektörünü temsil etmektedir. Denklem (3.15)'deki vektör otoregresif sürecinin birinci farkı alındığında:

$$
\Delta \mathbf{Y}_{\mathbf{t}}=\pi \mathbf{Y}_{\mathbf{t}-\mathbf{1}}+\sum_{\mathbf{i}=\mathbf{1}}^{\mathbf{p}-\mathbf{1}} \boldsymbol{\tau}_{\mathbf{i}} \Delta \mathbf{Y}_{\mathbf{t}-\mathbf{i}}+\mathbf{B X} \mathbf{X}_{\mathbf{t}}+\varepsilon_{\mathbf{t}}
$$




$$
\pi=\sum_{i=1}^{p} A_{i}-I \quad \text { ve } \quad \tau_{i}=-\sum_{j=i+1}^{p} A_{j}
$$

Burada $\boldsymbol{\pi}$ matrisinin indirgenmiş bir rankı olarak tanımlanan eşbütünleşme hipotezi, $\boldsymbol{\pi}=\boldsymbol{\alpha} \boldsymbol{\beta}^{\prime}$ biçiminde ifade edilmektedir. Denklem sonucunda, $\boldsymbol{\pi}$ matrisi tahmin edilmekte ve $\boldsymbol{\pi}$ 'nin indirgenmiş rankıyla belirtilen koşulların geçerliliği test edilmektedir. $\boldsymbol{\pi}$ matrisinin rankı, iz istatistiği ( $\boldsymbol{\lambda}_{\text {trace }}$ ) veya Max Eigenvalue istatistiği yardımıyla bulunmaktadır. İz istatistiği ile Max Eigenvalue istatistiği arasında bir tezat oluştuğunda, Max Eigenvalue testi daha kesin sonuçlar verdiği için tercih edilmelidir (Tarı 2014, 427). $\boldsymbol{\lambda}$ ve $\boldsymbol{\pi}$ matrislerinden elde edilen test istatistikleri JohansenJuselius (1990) tablo değerleriyle karşılaştırılır (Tarı 2014, 428).

Johansen yönteminin dezavantajı bağımlı ve bağımsız değişkenlerin aynı derecede durağan olduklarında uygulanmasıdır. Yöntemin avantajı ise, serilerin düzey değerleri kullanılarak uzun dönem analizi yapılması ve yapılan bu analizde daha fazla bilgiye yer vermesidir (Johansen 1988).

Tablo 7: Johansen Eşbütünleşme Testi

\begin{tabular}{|c|c|c|c|c|}
\hline Hipotez. & Trace İstatistiği & Kritik Dĕger (\%5) & $\begin{array}{l}\text { Max-Eigen } \\
\text { Istatistiği }\end{array}$ & $\begin{array}{ll}\text { Kritik Değer } \\
(\% 5)\end{array}$ \\
\hline$H_{0}: \tau=0, H_{l}: \tau=1$ & 37.14962 & 29.79707 & 28.46819 & 21.13162 \\
\hline$H_{0}: \tau \leq 1, H_{I}: \tau=2$ & 8.681430 & 15.49471 & 7.478394 & 14.26460 \\
\hline
\end{tabular}

Not: Johansen eşbütünleşme analizi için gerekli gecikme uzunluğu VAR yardımıyla SIC (Schwarz Information Criterion) kullanılarak 2 olarak belirlenmiștir.

İlk durumda hesaplanan test istatistikleri hesaplanan değerlerden büyük olduğu için seriler arasında eşbütünleşme ilişkisi mevcuttur. Yani ekonomik büyüme, enerji tüketimi ve finansal gelişme arasında yapılan analizlere göre elde edilen sonuçlar serilerin uzun dönemde birlikte hareket ettiklerinin ve bu serilerin uzun dönem analizlerinde sahte regresyon sorununun olmayacağının kanıtıdır. Johansen eşbütünleşme analizi sonucunda uzun dönem ve kısa dönem katsayılarının tahmini için VEC Modeli kullanılacaktır.

\subsection{VECM Modeli Eşbütünleşme Katsayılarının Tahmini}

Johansen eşbütünleşme testiyle aralarında eşbütünleşme tespit edilen, birden fazla açıklayıcı değişkenli modellerde, seriler arasındaki uzun ve kısa dönem analizleri, VECM yöntemi yardımıyla yapılabilmektedir.VAR modelinde kullanılan değişkenlerin durağanlıkları kontrol edildikten sonra durağan olmadıklarına karar verilirse, durağanlıklarını tespit etmek için birinci farklarını almak gerekmektedir. Bu durum sonucunda eşbütünleme analizi seriler arasındaki uzun dönem ilişkisini belirlemek için kullanılmaktadır ve serilerin farkları alındıktan sonra ortaya çıkan bilgi kaybına engel olmaktadır. Seriler arasında uzun dönem ilişkisinin belirlenmesinde serilerin aynı dereceden bütünleşik olmaları gerekmektedir. Seriler arasındaki Eşbütünleşme ilişkisi aşağıdaki denklemdeki gibi açıklanabilir (Bozuklu 2005, 82).

$$
\begin{aligned}
& x_{1 t}=\beta_{1}+\beta_{2} x_{2 t}+\beta_{3} x_{3 t}+\beta_{4} x_{4 t}+e_{t} \\
& e_{t}=x_{1 t}-\beta_{1}-\beta_{2} x_{2 t}-\beta_{3} x_{3 t}-\beta_{4} x_{4 t}
\end{aligned}
$$

Serilerin durağanlıkları belirlendikten sonra durağan olmayan seriler arasında uzun dönem denge ilişkisi varsa bu durum sonucunda değişkenlerin eşbütünleşik oldukları kabul edilir. Değişkenlerin uzun dönemde dengeden sapmalar göstermesi ve bu sapmalar zaman içinde dengeye doğru gelme durumuna hata düzeltme süreci denilmektedir (Brooks 2002,388).

$$
\begin{aligned}
& \Delta x_{1 t}=\alpha_{x 1}\left(x_{1 t}-\beta_{1}-\beta_{2} x_{2 t}-\beta_{3} x_{3 t}\right)+\varepsilon_{x 1 t} \\
& \Delta x_{2 t}=\alpha_{x 1}\left(x_{1 t}-\beta_{1}-\beta_{2} x_{2 t}-\beta_{3} x_{3 t}\right)+\varepsilon_{x 2 t} \\
& \Delta x_{3 t}=\alpha_{x 1}\left(x_{1 t}-\beta_{1}-\beta_{2} x_{2 t}-\beta_{3} x_{3 t}\right)+\varepsilon_{x 3 t}
\end{aligned}
$$

Hata düzeltme modeli 3 değişkenli ve gecikmesiz bir model için yukarıdaki denklemler şeklinde ifade edilebilir.

Burada $\left(\boldsymbol{x}_{1 t}-\boldsymbol{\beta}_{1}-\boldsymbol{\beta}_{2} \boldsymbol{x}_{2 t}-\boldsymbol{\beta}_{3} \boldsymbol{x}_{3 t}\right)$ denklemi serilerin uzun dönem denge değerlerini göstermektedir. $\alpha$ denklemlerdeki katsayıyı göstermektedir ve hata düzeltme katsayısı olarak ifade edilmektedir. Hata terimi olan $\varepsilon$ white noise özelliği taşımaktadır $\beta$ ise uzun dönem denge katsayısını oluşturmaktadır. 
Dogan, B., Deger, O. / Journal of Yasar University, 2016, 11/44, 326-338

Tablo 8: Eşbütünleşme Katsayıları Tahmin Sonuçları

\begin{tabular}{|l|c|c|}
\hline & Katsayı & \multicolumn{1}{c|}{-istatistiği } \\
\hline LnEnergy & 0.98 & -5.78 \\
\hline LnFD & 0.18 & -0.67 \\
\hline Sabit Terim & -0.35 & -4.14 \\
\hline ECT $\boldsymbol{t}_{\text {-1 }}$ & -0.07 & \\
\hline \multicolumn{2}{|c|}{} & $\bar{R}^{2}=0.31 \quad F=5.71$ \\
\hline
\end{tabular}

Tablo 7'deki sonuçlara göre; enerji tüketiminde meydana gelen \%1'lik artış ekonomik büyümeyi \%0.98 oranında arttırırken, finansal gelişmedeki \% 1 'lik artış ekonomik büyümeyide \%0.18 oranında artırmaktadır. Modelin hata düzeltme katsayısının işareti negatif ve istatistiksel olarak anlamlıdır. Yani uzun dönemde birlikte hareket eden bu seriler arasında kısa dönemde meydana gelen sapmalar ortadan kalkmakta ve seriler tekrar denge değerine yakınsamaktadır. Bu durum, elde edilen uzun dönem eşbütünleşme katsayılarının güvenilir olduğuna da bir delil teşkil etmektedir.

\section{Sonuç}

Son yıllarda ekonomik büyümeyi hedefleyen ülkelerde özellikle enerji tüketimlerinde önemli bir artış olduğu karşımıza çıkan çalışmalarda görülmektedir. Bu çalışmada son yıllarda önemli bir şekilde ekonomik gelişme gösteren Hindistan örnekleminde zaman serisi analizi yapılmıştır. Yapılan analiz sonucunda ekonomik büyümeden enerji tüketimine doğru bir nedensellik ilişkisi bulunmuşken enerji tüketiminden ekonomik büyümeye doğru bir nedensellik ilişkisi bulunamamıştır. Ayrıca ekonomik büyümeden finansal gelişmeye doğru bir nedensellik ilişkisi mevcutken finansal gelişmeden ekonomik büyümeye doğru bir nedensellik ilişkisi bulunamamıştır. Serilerin uzun dönemde eşbütünleşik olduğuna karar verebilmek için ekonomik büyüme, enerji tüketimi ve finansal gelişme serileri birden fazla bağımsız değişken olduğu durumlarda kullanılan Johansen eşbütünleşme analizine tabi tutulmuştur. Yapılan analiz sonucunda seriler arasında eşbütünleşme olduğuna karar verilmiştir. Seriler arasında eşbütünleşme ilişsisi tespit edildikten sonra VECM yöntemiyle serilerin uzun dönem ve kısa dönem ilişkisi incelenmiştir. VECM sonuçlarına göre uzun dönemde enerji tüketiminde meydana gelen $\% 1$ 'lik artış ekonomik büyümeyi \%0.98 oranında arttırırken enerjinin $t$-istatistik katsayısı anlamlıdır. Yine uzun dönemde finansal gelişmede meydana gelen \%1'lik artış ekonomik büyümeyi \%0.18 oranında artırmaktadır. Bu çalışmada elde edilen analiz sonuçları literatürde; Cheng (1999); Ghosh (2002); Yemane (2004); Lise ve Montfort (2005); Öztürk vd. (2010); Shahbaz vd. (2013a); Topallı ve Alagöz (2014) tarafından yapılan çalışmalar ile paralellik göstermektedir. Ampirik sonuçlara göre ekonomik büyüme enerji tüketimini uyarmaktadır. Bu açıdan gelişmekte olan ülke olan Hindistan'da gerçekleşen ekonomik ilerleme ile imalat sektörlerinde kullanılan enerji tüketimi büyümeyi hızlandırmaktadır. Bu durumda Hindistan'ın büyüme ile birlikte artış gösterecek olan enerji talebini anında karşılayabilmek için enerji arzını çeşitlendirme yoluna gitmesi ve bununla ilgili etkin politikalar geliştirmesi önem arz etmektedir. 
Dogan, B., Deger, O. / Journal of Yasar University, 2016, 11/44, 326-338

\section{KAYNAKÇA}

Ahmad A., Zhao Y. Shahbaz M. Bano S. Zhang Z. Wang S. ve Liu Y. 2016. "Carbon emissions, energy consumption and economic growth: An aggregate and disaggregate analysis of the Indian economy". Energy Policy, 96:131143.

Apergis, N., ve Payne, J.E. 2009. "Energy Consumption and Economic Growth in Central America: Evidence From A Panel Cointegration and Error Correction Mode". Energy Economic, 31(2): 211-216.

Asafu-Adjaye, J. 2000. "The Relationship Between Energy Consumption, Energy Prices and Economic Growth: Time Series Evidence From Asian Developing Countries". Energy Economic, 22(6): 615-625.

Aytaç, D. 2010. "Enerji ve Ekonomik Büyüme İlişkisinin Çok Değişkenli Var Yaklaşımı İle Tahmini”. Maliye Dergisi, 158: 482-495.

Barışık, S. ve Demircioğlu, E. 2006. “Türkiye’de Döviz Kuru Rejimi, Konvertibilete, İhracat-İthalat İlişkisi (1980-2001)". Zonguldak Karaelmas Üniversitesi, Sosyal Bilimler Dergisi 2(3): 71-84.

BP Dünya Enerji İstatistikleri, http://www.bp.com/en/global/corporate/about-bp/energy economics/statistical-review-ofworld-energy.html, Son Erişim:29.12.2015.

Bozoklu, Ş. 2005, Banka Kredisi Aktarım Mekanizması: VAR Yaklaşımı, Basılmamış Yüksek Lisans Tezi, İstanbul Üniversitesi

Bulut, C., Hasanov ve F. ve Süleymanov, E. 2014. “ Enerji Kullanımıve Ekonomik Büyüme İlişkilerinin Teori ve Ekonomi Politikaları Açısından Değerlendirilmesi”. http://papers.ssrn.com/sol3/papers.cfm?abstract_id=2433142. Son Erişim: 23.12.2015.

Cheng, B.S., 1999. "Causality Between Energy Consumption and Economic Growth in India: An Application of Cointegration and Error-Correction Modeling". Indian Economic Review, 34(1): 39-49.

Dickey, D. A. 1981. "Histograms, Percentiles, and Moments”. American Statistician, 35:164-165.

Dritsaki, C. ve Dritsaki, M. 2014. "CO Emissions, Energy Consumption, Financial Development and Economic Growth: A Multivariate Cointegration and Causality Analysis for Greece”. World Applied Sciences Journal, 32 (2): 309 321.

Engle, R.F. ve Granger, W.J. 1987. "Cointegartion and Error Correction:Representation, Estimation, and Testing". Econometrica, 55: 107-123 ve 251-276.

Esseghir A. ve L. H. Khouni 2014. "Economic Growth, Energy Consumption and Sustainable Development: The Case of the Union for the Mediterranean Countries". Energy, 71: 218-225.

Fowowe B. 2012. "Energy Consumption and Real GDP: Panel Co-Integration and Causality Tests For Sub-Saharan African Countries". Journal of Energy in Southern Africa,23(1):8-14.

Ghosh, S. .2002. "Electiricity Consumption and Economic Growth in India". Energy Policy, 30(2): 125-129.

Göçer İ. ve Peker O. 2014. "Yabancı Doğrudan Yatırımların İstihdam Üzerindeki Etkisi: Türkiye, Çin ve Hindistan Örneğinde Çoklu Yapısal Kırılmalı Eşbütünleşme Analizi”. Celal Bayar Üniversitesi İ.I.B.F. Yönetim ve Ekonomi Dergisi, 21(1): 107-123.

Göçer, İ. ve Özdemir, A. 2012. "2008 Küresel Krizinin Yayılma Süreci ve Etkileri: Seçilmiş Ülkeler İçin Ekonometrik Bir Analiz”. Afyon Kocatepe Üniversitesi, Yönetim ve Ekonomi Araştırmaları Dergisi, 17:18-37.

Gövdere, B. ve Can M. 2015. "Enerji Tüketimi Ve Ekonomik Büyüme İlişkisi: Türkiye Örnekleminde Eşbütünleşme Analizi”. Uluslararası Iktisadi ve İdari Bilimler Dergisi, 1(2): 101-114.

Gövdere, B. ve Can, M. 2016. “Türkiye'de Enerji Tüketimi, Dışa Açıklık, Finansal Gelişme, Sabit Sermaye Yatırımları Ve Dış Ticaretin Ekonomik Büyümeye Etkisi: Sınır Testi Yaklaşımı”. Niğde Üniversitesi İktisadi Ve İdari Bilimler Fakültesi Dergisi, 9(1): 209-228.

Granger, C.W.J. 1969. "Investigating Causal Relations by Econometric Models and Cross-spectral Methods". Econometrica, 37(3): 424-438.

Johansen, S. 1988. "Statistical Analysis of Cointegration Vectors". Journal of Economic Dynamic and Control, (12): 231254.

Johansen, S. ve Juselius, K. 1990. "Maximum Likelihood Estimation and Inference on Cointegration With Application to the Demand for Money". Oxford Bulletin of Economic and Statistics, 52: 169-210.

Karaçor, Z. ve Gerçeker, M. 2012. "Reel Döviz Kuru ve D1ş Ticaret İlişkisi: Türkiye Örneği(2003-2010)". Selçuk Üniversitesi, IIBF Sosyal ve Ekonomik Araştırmalar Dergisi, 23:289-312.

Komal R. ve Abbas F. 2015. "Linking financial development, economic growth and energy consumption in Pakistan". Renewable and Sustainable Energy Reviews, 44: 211-220

Kraft, J.,ve Kraft, A., .1978. "On the Relationship Between Energy and GNP”. Journal of Energy and Development, 3 (2): 401-403.

Le, K-S., Gasbarro D. ve Gullen, G. 2014. "The Relation between Financial Development, Energy Consumption and Economic Growth: Empirical Evidence for the United States. 27th Australasian Finance and Banking Conference". http://papers.ssrn.com/sol3/papers.cfm?abstract_id=2484279, Son Erişim: 19.02.2016. 
Lise W. ve K. Van Montfort. 2005. “Energy Consumption and GDP in Turkey: Is There A Co-Integration Relationship?”. Paper presented at EcoMod2005 International Conference on Policy Modeling, Istanbul, Turkey.

Mackinnon, James. G. 1996. "Numerical Distribution Functions For Unit Root And Cointegration Tests". Journal of Applied Econometrics, 11:601-618.

Mucuk, M. ve D. Uysal, 2009. “Türkiye Ekonomisinde Enerji Tüketimi ve Ekonomik Büyüme” Maliye Dergisi, 157:105115.

Odhiambo, N. M. 2009. "Energy Consumption and Economic Growth Nexus in Tanzania: An ARDL Bounds Testing Approach". Energy Policy, 37, 617-622.

Omay T., M. Hasanov ve N. Uçar 2012. "Energy Consumption and Economic Growth: Evidence From Nonlinear Panel Cointegration and Causality Tests". MPRA Paper No:37653.

Ozturk, I.,A., Aslan ve H.Kalyoncu 2010. "Energy Consumption and Economic Growth Relationship: Evidence From Panel Data for Low and Middle Income Countries”. Energy Policy, 38:4422-4428.

Paul, S., ve Rabindra N. Bhattacharya 2004. "Causality Between Energy Consumption and Economic Growth In India: A Note on Conflicting Results”. Energy Economics, 26:977 -983.

Phillips, P.C.B, ve Perron, P. 1988. “Testing For A Unit Root İn Time Series Regressions”. Biometrika 75: $335-346$.

Pempetzoglou M. 2014. "Electricity Consumption and Economic Growth: A Linear and Nonlinear Causality Investigation for Turkey". International Journal of Energy Economics and Policy, 4(2): 263-273.

Perron, P. 1990. "Testing For A Unit Root in A Time Series With A Changing Mean". Journal of Business and Economic Statistics, 8: 153-62.

Saatçi M. ve Y., Dumrul (2013). "Elektrik Tüketimi Ve Ekonomik Büyüme İlişkisinin Dinamik Bir Analizi: Türkiye Örneği”. Uludağ Üniversitesi İktisadi ve İdari Bilimler Fakültesi Dergisi, 32(2):1-24.

Sadorsky, P. 2010. "The Impact of Financial Development on Energy Consumption in Emerging Economies". Energy Policy, 38: 2528-2535.

Sadorsky, P. 2011. "Financial Development and Energy Consumption in Central and Eastern European Frontier Economies". Energy Policy, 39: 999-1006.

Sadorsky, P. 2012. "Energy consumption, output and trade in South America”. Energy Economics, 34(2): $476-488$.

Salman D. M. ve Etya, E. M. 2014. "What is the role of Financial Development and Energy Consumption on Economic Growth? New Evidence from North African Countries". International Journal of Finance \& Banking Studies IJFBS, 3(1): 137-149.

Shahbaz M., S. Abosedra ve R. Sbia 2013a. "Energy Consumption, Financial Development and Growth: Evidence From Cointegration With Unknown Structural Breaks in Lebanon”. MPRA Paper No. 46580.

Shahbaz, M., S. Khan ve M. I. Tahır 2013b. "The Dynamic Links Between Energy Consumption, Economic Growth, Financial Development And Trade in China: Fresh Evidence From Multivariate Framework Analysis". Energy Economics, 40: 8-21.

Shahbaz, M., ve Lean, H.H. 2012. "Does Financial Development Increase Energy Consumption? The role of Industrialization and Urbanization in Tunisia". Energy Policy, 40:473-479.

Siddique, H.M.A. ve Majeed, M.T. 2015. "Energy Consumption, Economic Growth, Trade and Financial Development Nexus in South Asia". Pakistan Journal of Commerce and Social Sciences, 9(2): 658-682.

Stock, James, H. ve Watson Mark,W. 1993. "A Simple Estimator of Cointegrating Vectors in Higher Order Integrated Systems". Econometrica, 61(4): 783-820.

Tarı, R. 2014. Ekonometri. 10.Bask1. Kocaeli: Umuttepe Yayınları.

Topallı N.ve M.Alagöz 2014. "Energy Consumption and Economic Growth In Turkey: An Empirical Analysis”. Selcuk University Journal of Institute of Social Sciences, 32:151-159.

Tsani, S. 2010. "Energy Consumption and Economic Growth". Energy Economics, 32(3): 582-590.

Uçan,O.,E.Arıcıoğlu ve F.Yücel 2014. "Energy Consumption and Economic Growth Nexus: Evidence from Developed Countries in Europe”. International Journal of Energy Economics and Policy,4(3): 411-419.

Uzgören, N., Ceylan, G. ve Uzgören, E. 2007. "Türkiye'de Kredi Kartı Kullanımını Etkileyen Faktörleri Belirlemeye Yönelik Bir Model Çalışması”. Celal Bayar Üniversitesi İ. I. B. F. Yönetim ve Ekonomi, 14 (2):247-256.

World Bank Data, http://data.worldbank.org/indicator/NY.GDP.PCAP.CD. Son Erişim: 28.12.2015.

World Bank Data,http://data.worldbank.org/indicator/FS.AST.PRVT.GD.ZS.Son Erişim:28.12.2015.

Yang, H. Y. 2000. “A Note on the Causal Relationship Between Energy and GDP in Taiwan”. Energy Economics, 22: 309-317.

Yemane W. R. 2004. "Electricity Consumption and Economic Growth: A Time series Experience for 17 African Countries". Energy Policy, 34(10):1106-1114. 